\title{
E-Petitioning in Environmental Matters in Romania: Is It an Effective Environmental Governance Tool?
}

\author{
Raluca Suciu $^{1}$
}

\begin{abstract}
E-petitioning related to environmental matters is a rather new participatory behavior in the Romanian society and it seems to attract more and more the attention of a larger public (not just a minority of educated eco-citizens or experts in related fields). Lately, in Romania there were a few major e-petitioning campaigns trying to stop large and popular economic investments projects that were detrimental to the environment (the most visible are petitions fighting the building of microdams on mountain rivers, regional landfills, mining projects). Also, those campaigns led to media coverage, brought on a public debate through some media channels, revealed serious problems with how the state authorizes such projects, and even managed to get the attention of the European Commission. None of these would have been possible without the very source of large public mobilization on an environmental matter, e-participation and e-petitions.
\end{abstract}

Thus, the paper investigates e-petitions in the environmental field in order to understand their impact on environmental problems, and also, most importantly, if these e-petitions manage to influence environmental policy and governance. For decades, through the entire process of European integration, Romania has struggled with meeting the environmental standards required by the EU. Data is lacking or unreliable, there is a culture of lack of transparency related to environmental matters both in the public and in the private sector, and Romania needs to seriously address this problem. The paper provides an investigation of 'if' and 'how' e-petitioning could be a tool to move state and society towards effective environmental governance in the Romanian context.

\section{Public participation and its role in environmental governance}

The paper places the subject of e-petitions in the wider context of environmental policy making and governance, in order to understand the role they play in facilitating public involvement and good governance. Some insights into the theoretical aspects of participation and governance and a minimal diagnosis of the level of participation and governance manifestations in Romania are necessary in order to provide context for environmental e-petitioning and understanding why this movement is so important for the Romanian context. Given the scope of this paper, the most relevant theoretical issues in relation to the research subject are selected.

With regard to public participation the theoretical approaches are numerous and rich in significance when applied to environmental governance.

A minimal definition of participation includes any type of involvement of non-state actors, as members of the public or as organized stakeholders, in any stage of governmental policy making including implementation [9]. The general purpose of participation is to contribute to the quality and implementation of decisions as well as their legitimacy.

\footnotetext{
1 Public Administration and Management Department, Faculty of Political, Administrative and Communication Sciences, Babes-Bolyai University, Gen. Traian Mosoiu, 71, 400132, Cluj-Napoca, Romania, raluca.suciu@fspac.ro
} 
Research into the rationales for public participation resulted in recent studies proposing comprehensive and easily applicable models; thus, Wesselink et al. (2011) discuss three major rationales for participation: instrumental - targeting increased legitimacy of policy decisions and improved results; substantive - increasing information input, gives more substance to proposals, makes decisions that address problems in as much depth as possible, improving the quality of decisions; and normative - linked to democratic ideals and values, including all affected parties into policy decisions for fostering maximum public involvement. Different from this theoretical categorization, other approaches try to identify all the possible benefits and justifications for public participation. One such rationale that applies in particular to our discussion is resolution of political and societal conflicts by means of alternative mechanisms and empowerment of marginalized groups which have been left out of environmental governance.

Although the literature in this field is large and comprehensive, the discussion will be limited to elements applicable to the situation of environmental governance in Romania. Rather the legalistic rationale applies to the Romanian public administration, central government and central agencies included. This rationale, proposed by Wesselink et al. (2011), applies for participation organized only to meet formal requirements. Compliance with rules is necessary to get things done, but this process is likely to be only a formality without any uptake of results [9].

There is relevant literature analyzing the rationales and discourses used by public authorities in participatory processes [7], but there are fewer attempts at theorizing the participants' discourses on participation, mostly based on a case-study approach.

Recently, the environmental governance literature addresses the need for a transformative change needed in order to address the most important global environmental problems (climate change, ecosystem sustainability). There seems to be a consensus that the status-quo is not working for environmental protection. Following from this, methods and models to improve environmental governance are addressed in most studies: transformative changes that are invoked in the literature need large involvement and participation - thus the relevance of public participation and the extensive interest in the best ways to consolidate it.

Basically, studies on participation try to address ways 'to create rapid mobilization that will educate the public about environmental issues and raise social consciousness with regard to the need for policy reform that will support more radical approaches to environmental problems' [6].

According to Jacoby (2012), in this new paradigm, the role of the public is fundamentally changed, from stakeholder of an environmental resource (term which implies opposition, polarization, protecting one's stake) to partner in social and political change efforts needed to address environmental issues. This shift in perspective is characteristic to recent literature development in public participation in environmental policy and governance [6].

Another relevant argument is that there is a perfect fit between these recent developments in environmental governance and the new e-communication tools that are so ubiquitous in this age.

Disappointment with traditional public authorities led public participation, such as public hearings or formal public consultations, originates in the lack of empowerment through such processes, cynicism with regard to the ability to influence decisions, opposition, polarization (jobs versus the environment), and even the need for litigation from communities. 
All these failures of traditional paths for public involvement have given rise to new bottom-up participatory trends in environmental decision-making. Informal community-based evidence with regard to environmental problems and other manifestations of informal environmental leadership can allow communities to create change and empower citizens, if they succeed in finding an effective way into the policy process (either by relevance of information and/or by extent of public involvement). Basically, new e-communication tools are creating new opportunities for these invisible informal leaders (citizen leaders) to create collaboration, consensus and compromise, opportunities for inclusiveness and shared power rather than just articulate dissent (as in the case of public meetings or formal policy dialogue) or communicate information to decision-makers.

In time, these online groups become virtual communities united by core beliefs and values that further motivate their civic behavior and influence public opinion and decision-making at policy level. Socio-ecological problems at the heart of environmental policy are much too complex to be dealt with through simplistic procedures, thus the need for a new paradigm for citizen involvement in environmental issues and new tools that can respond to the exigencies of contemporary public participation [8].

\section{Environmental governance in Romania, the role of public participation}

This section consists in an explanation for the state of environmental governance and public participation in environmental matters in Romania: the process of development and implementation of environmental policy in post-socialist Romania has prevented public involvement in environmental policy and establishment of stable patterns of cooperation with non-state actors.

In Romania, central government agencies play the main role in environmental decision-making so, traditionally, the citizens must turn to government in attempts to protect the environment and their quality of life. Public participation procedures and the way the authorities understand to manage them clearly do not have as a result efficient environmental problem solving, with adequate community consensus and participation. Citizens or civil organizations attempting to participate in these procedures with the intention to influence decisions in early stages of environmental decisionmaking are frustrated by the lack of transparency of these meetings, the adversarial character, time limits, lack of dialogue, lack of expertise or expert advice, that they occur too late, when decisions are too advanced to influence the outcome, that they find an already made coalition with economic interests (recently this happened in the context of waste regulation [4], [2]). Citizens are also frustrated by the consultative character of the public hearings and lack of impact of participation in the outcome.

As a result, participation is limited in Romania and there is an acute need for solutions in order to make environmental decision-making more transparent, inclusive and legitimate. Adoption of EU top-down environmental policy (especially during accession negotiations) means that environmental policy in Romania did not pass through a participatory process in order to look for solutions for environmental problems, but was rather a top-down policy implementation, which became mostly ineffective due to the fact that it was not connected to any environmental values. These environmental values are missing, both in the public sector and in society in general, together with environmental literacy (e.g. sustainable development, climate change, carbon literacy, etc.). Even if, from a legalistic perspective, the Romanian environmental legislation transposes the participatory mechanisms included in the EU Directives (e.g. Council Directive 92/43/EEC Habitats Directive; Directive 2000/60/EC - Water Framework Directive; Directive 96/61/EC - 
IPPC Directive), there is a huge gap between legal provisions and their superficial implementation, leading to a participation deficit in environmental policy making in Romania.

This diagnosis comes at a time when environmental literature discusses participation fatigue in countries implementing different tools and methods designed to increase public participation in environmental decision-making (based on research efforts to understand the rationales for participation from the perspectives of all stakeholders). If the recent specialized literature discusses a shift from stakeholder to citizen leadership, than the case of Romania is different: in order to implement the latest developments in participation we would have to jump over the stakeholder phase, since stakeholder involvement did not effectively happen in environmental decision-making in Romania.

The Aarhus Convention, giving free access to environmental information also applies in Romania, but transparency is limited because institutions do not collect or integrate some of the most basic data that would be of interest to the public. Also, there is no pro-active approach to public information; in 2016 there was a petition of several environmental organizations requiring that the Ministry and National Environmental Protection Agency offer decent websites to the public, with relevant information (still unresolved). Even some legal documents (annexes to Minister's Orders are not publicly available, some of them are only available as hard-copy at the Official Journal of Romania, in the capital city and can be accessed only with pay at their institutional headquarters).

In one relevant study of environmental governance in Romania, Buzogány (2009) illustratively used the syntagm 'forms without substance' to describe the situation in Romania where, formally, there are some governance mechanisms present in the legal framework and implementation methodologies, but no real manifestation of those governance mechanisms in the policy process (formal role of consultative bodies, formal or only reported public consultation, formal public information and limited public access to information, no impact of stakeholders other than state or industry lobby in policy decisions) [1].

Important barriers to public involvement come from the heritage of socialist environmental policies and the problems of the transition and accession periods: no or low priority for the environment in policy; institutional fragmentation; preference for and prevalence of the command and control approach to environmental policy; an administrative culture hostile to public participation; frequent institutional changes; political appointments in environmental protection institutions at central and local level (personnel appointed by central political government). So, there was little room for civil society involvement (and this also influenced the development and profile of the civil society).

Competencies in environmental policy fields are mostly centralized, implementation and control is done by central state agencies with sub-structures in the sub-national administrative units and responsible to the central agencies (top-down steering and control), leaving little space for new provisions of participation mechanisms relevant in the context of environmental governance.

\section{E-petitions as part of digital environmentalism}

The e-petition is a participatory instrument linked closely to other new emergent concepts in the field of environmental governance - online ecosystem, digital environmentalism, and democratization of science. 
There are both opportunities and risks that come with these new approaches to participation in environmental governance. Opportunities come from several particularities of online participation: ideas can be presented incomplete, as work in progress, and can be refined in the process of online public participation (for e-petitions through commentaries made by supporters and signatories), fostering local knowledge, and experiential knowledge from those who work closely or in relation to the issues addressed. There is also a huge opportunity stemming from the larger access to the general public, more specifically turning the elitist environmental movement (this is largely the case in Romania, where experts, practitioners, community activists and highly educated people are part of a minority environmental civic movement) into a broader social movement. This happened, using mostly social media for several months in 2013-2014, with street protests peaking in January 2014 to oppose cyanide mining projects in Romania. These protests were considered the largest protests since 1990, and they were followed by mobilization of this larger community by e-petitioning to initiate and keep a close scrutiny on proposals to modify the mining legislation.

Other opportunities come from timely or in real time reporting possibilities, and continuing conversations after significant events (legislative adoption can be followed through implementation), monitoring new developments (especially important for environmental problems, which manifest complexly in time and space and for environmental policy, which is subject to complex interactions with other policy fields).

One risk is that these communities are built on shared ideas and values and there is not enough dissent to develop complete and refined participatory tools through e-petitions. Environmental organizations were clearly favored by the use of online tools, having the opportunity to reach a large audience, but this also entails the risks associated with 'democratizing science' - experts and simple citizens have the same status and reach in online communities, dialogue is not always constructive or conclusive, arguments with different weights are competing in the same arena. It is difficult to manage science-informed policy or governance agendas specifically because of this greater number of participants in the debate (visible in climate change governance). Closely related to this risk, there is the risk of capture from misleading or malevolent parties promoting pseudoscience, denialism, conspiracy theories, the newer 'alternative facts' approaches. Greenwashing, usually done by companies but also by other organizations pretending to work for the environment, is also a potential risk, since it is facilitated by use of online tools.

The most compelling critiques to e-participation in general and e-petitioning in particular come from the activists themselves. The term used for signatories of online petitions with no other positive contribution to follow the environmental policy process is 'slacktivism'. It includes behaviors such as liking or sharing on social media networks, signing petitions, confirming participation to real-life events but never actually participating (armchair activism), having no real involvement or engagement with the issues brought about by the activist movement [8].

However, the same literature shows that there is significant advantage for environmental organizations who manage to keep a large, active, well-connected network, which has as a main advantage the unimpeded flow of information. These organizations themselves report that the size of the network compensates for slacktivism or less-engaged membership [8].

\section{Research methods}

The manifestations of participation through e-petitions in environmental matters were analyzed by two methods: content analysis of petitions and semi-structured expert interviews. 
The research endeavor was more of an exploratory one, rather than to test specific research questions with regard to e-participation. The attempt to describe and understand the potential of green e-petitioning was guided by a few general assumptions:

- $\quad$ Citizens are in a position to raise new facts, concerns, and questions in order to require public agencies to further research the implications of environmental decisions.

- $\quad$ The e-petition has the potential to be an effective governance tool.

- The e-petition has the potential to contribute to the resolution of political and societal conflicts by means of alternative mechanisms and empowerment of marginalized groups which have been left out of environmental governance.

\subsection{Content analysis of petitions}

In order to understand e-petitioning in environmental matters in Romania the environmental epetitions available on the Romanian online platform https://www.de-clic.ro/ were analyzed. Given the author's expertise in environmental policy, the subjects addressed by the petitions were familiar and thus an assessment of the overall quality of the arguments brought, of the requests made and the general overlap (if any) of the discourse with other interests was possible.

There is an opportunity provided by e-petitions to communicate directly to the public, making it possible to foster large support for the environmental issue presented in the petition that is not possible for other participatory mechanisms, such as public hearings or consultations. Resulting from this advantage of the e-petition, the research assumption was that analysis of the types of issues addressed by citizens, of the arguments brought, or the difficulties expressed with regard to civic involvement (including in the comments sections), would offer a better understanding of the environmental policy process.

The content analysis observed:

- $\quad$ Analysis of petitions' content available on the site (quality of arguments and requests);

- $\quad$ Subject of the petition (if it is reactive to government failures or market failures);

- Analysis of discourse on participation and environmental governance underlying these petitions (independent on the subject of the petition);

- If there is an assumed identity and interest of petitions' initiators (stakeholder, collaborator, consultant, part in a conflict) or if such identity can be inferred from the discourse and arguments.

In total over 200 e-petitions were reviewed. The platform is dedicated to any subjects of concern for civil society, but the vast majority of petitions are environment-related (e.g. labelled public health but contesting the authorization awarded to an air polluting company, or addressing public transportation or water quality issues, etc.). Signing of the e-petition on this particular electronic platform (de-click.ro - civil society in action) requires providing information on name, family name, e-mail address, phone number and county of residence. Thus there is no verification and validation procedure for the individual signatures by citizens. There is no reference in the Romanian 
legislation on petitioning with regard to electronic petitions addressed to public institutions or electronic signatures of citizens (only that petitions can be sent by electronic mail and that identification data of the petitioner are required) [5]. However, lists of such electronic signatures were annexed to petitions lodged with authorities and were accepted (thus a response was provided to the person/organization who assumed the identity of petitioner, providing address, phone, e-mail, but no personal identification numbers or other proof of identity are required).

The content analysis revealed some surprising facts. The expertise level of the majority of the petitons is very high and high, in direct relation to the complex subjects they address. The most extensive and successful petitions were for saving a protected river from micro-hydro (almost 50,500 signatures), proposal of Rosia Montana for UNESCO World Heritage status (10,800 signatures), banning cyanide mining (multiple petitions, until now they managed to bring legislative modifications proposals). The e-petitions are very well documented and provide quality information, in a comprehensive style, with links to additional sources. The quality of the requests is very high. They indicate very clearly the measures required from the authorities with exact legal reference and legal justifications for additional measures (including litigation). There is extensive follow-up to the most important petitions, the feedback given to signatories is timely and complete, giving an exact image of the development of the problem. Also, in order to test the language of the petitions on non-experts, with the purpose to see if the e-petitions are too complex for non-experts, first year students were asked to read, comment, explain their understanding of the petition (students from the Public Administration program who did not take a course in environmental science by that time). The conclusion was that, with the exception of some legal references, they could understand the problem stated, the context and what the e-petition asked from the authorities. A minority of the petitions (less than 20\%) seem to be initiated by non-experts. They address environmental matters of community interest (saving a local river from extending road infrastructure, allocation of road space to buses and bikes, stopping waste incinerators projects, closing down toxic waste deposits, etc.). The language is clearly different, less expert, although very clear and coherent problem framing and requests are made. Overall, the e-petitons are extremely well documented and, as tested on non-experts, can speak clearly to non-experts. It is probably a factor of their success in reaching large audiences (in 2016, the platform reported over 120,000 individual signatures).

A vast majority of the petitions are reactions to government failures. They denounce the environmental problem as a mix of market and government failures, but there are always presented breaches of legislation, lack of consultation, illegal influence of interest groups. The requirements are for measures to be taken by the competent authorities in order to review documents, authorizations, decisional processes and include arguments of the public in their decision. A lot of the petitions demonstrate illegal practices of competent authorities (related to waste, mining, forest management, protection of natural areas, including Natura 2000 sites). Some of these breaches are confirmed by European Commission investigations and NGOs. Only 4 campaigns framing the problem exclusively as a market failure were identified, all related to forest management and wood processing and selling. E-petitons were addressed to Holzindustrie Schweighofer, accused of buying illegally cut wood, Forest Stewardship Council, accused of providing unverified certification to the company, and large retailers accused of selling products resulting from illegal wood cutting (the story was extensively covered by the media and involved environmental NGOs from all over Europe, resulting in the decision of Forest Stewardship Council to revoke the sustainability certification [3]). 
Only a minority of e-petitons address larger environmental governance issues (framing the problem also as one directly linked to transparency, access to information, lack of public involvement) and stressing the overall importance of participation for the quality of the environment and the public interest.

Very complex petitions mentioned all the initiators and important campaigners, smaller / narrower petitions are signed by a natural person (with full name), no e-petitions were found that seemed manipulating or deceiving or trying to promote other interests, that are in contrast to the environmental character of the petition. Overall, the platform is transparent enough with regard to sources of support, campaigners and activists involved.

\subsection{Analysis of expert interviews}

For conducting the semi-structured interviews experts in the environmental field were selected, based on their involvement at least once in organizing a participatory process related to environmental policy-making from the perspective of stakeholders other than the state authorities. A preliminary discussion and prior collaboration ensured that the experts had an understanding of the environmental governance in Romania, the general context in which participation in environmental matters happens in order to make sure that their responses reflect an overall view of the policy process, not just their individual experience with participation (since experts were asked to discuss the opportunities offered by the online methods). The short questionnaire did not include references to the normative framework of participation or governance; rather the aim was to identify a conceptual pattern in the answers in the analysis phase.

During January 2017 requests for interviews were sent by e-mail to experts from the private sector (consultants) and civil society organizations. Only 6 experts accepted a lengthy interview (2 by phone), some preferred to send answers by e-mail (and were only partially used in this analysis).

The instrument was developed around 4 major issues regarding e-petitions: potential impact on the policy decisions, expectations from this form of e-participation (other than to influence decisions), the role of e-petitioning in environmental governance, opinion on the virtual environmental communities in Romania. Not all the questions and all relevant answers were included in the paper, due to space limitations.

The first question in the interview regarded the potential impact of e-petitions on the environmental policy process and specifically decisions in environmental matters.

Discussions with experts were complex and rich in examples from other countries where e-petitions are largely used by the public. There is a general opinion expressed in the interviews that it is difficult to measure the impact of e-petitions on the policy decisions. Even if the policy decision reflects the requests of e-petitions, there is no final conclusion that the e-petitions resulted in that decision. The policy process is complex, and there should be a complete analysis of all the stakeholders' input in order to determine if and how interests converged and what other external pressures were exerted. None of the experts was willing to say that environmental decisions can be influenced in a significant way by the use of e-petitions. The experience of working with public authorities consolidates the opinion that in Romania the most influent forces do not manifest publicly and transparently and public authorities do not openly report on decision-making processes (similar to the rapporteur procedure of the European Parliament, for instance). This question started the most interesting discussion during the interviews and other topic-related discussions, but they 
were not about e-petitions, but rather about problems in Romania with the environmental policy process and its lack of transparency. To conclude, experts (the author included) did not believe in the potential of e-petitions to significantly influence environmental decisions if are not followed by other participation mechanisms that involve a more 'physical' pressure on public authorities.

Following this quite pessimistic discussion, the next objective was to see if there is any role of epetitioning in environmental governance.

From the responses it results that e-petitioning as a societal participatory behavior is an important driver for good environmental governance. The experts' responses made reference to education, rising public awareness, creating a sense of community, disseminating important information, creating a general understanding of the relationships between environment and quality of life (creating an individual stake in environmental participation), fostering a general attitude of support for the environmental agenda.

Most significantly, the respondents stressed the importance of values and value-driven participation in society in general, and the underlying problem of missing environmental values of the general public. There is clearly a long way to go from public sector formal requirement of participation to a widespread culture of participation, and it is hard to say where exactly participation drivers should be placed first. With a general disappointment in the state capacity to follow long term strategies and the public interest (especially after the last election, since interviews took place in January 2017), the majority of respondents placed their bet on the civil society organizations and external support for such organizations. This view influenced the unanimous recognition of e-petitions as a potential tool for spreading environmental values, and fostering public education and civic engagement in environmental matters. However, as stated above, there is little hope with regard to the measurable outcomes of e-petitioning in the environmental field. The experts say there are no real pressures for the authorities, that public officials react to established interest and lobby groups and easily ignore this 'light' form of activism.

Do e-petitions increase public participation of the non-experts? Is this participation meaningful for environmental governance?

To summarize the experts' opinions - yes, but this is not necessarily important for the policy decisions made in the environmental field in Romania. It is important from a governance perspective, if we consider that these examples of participation are among the very few arguments for the existence of any forms of environmental governance in Romania (other than the command and control approach to policy). In terms of outcomes, the environmental movement still relies on expert participation.

As an expert, what would be legitimate expectations regarding participation through e-petitions in Romania?

For this question, experts observed that it should be addressed to those involved specifically in epetitioning campaigns, since they could discuss their expectations. In terms of the role that could be played by e-petitioning, respondents saw the use of e-petitions to be linked more with objectives such as raising awareness, education and signaling a specific acute environmental problem (and were not sure that initiators of e-petitions have as an expectation public education and not the more tangible objective of solving a problem). The respondents saw limited role or contribution of epetitions to more complex outcomes of participation, such as quality of policy-making, legitimacy 
of decisions, adding relevant information to the decision-making process (the normative and substantive rationales identified in theory). One respondent said that in his participation procedures 'they had their eyes on the prize', no long-term goals were attached to the participation process. After reflection on responses, the conclusion was that expectations related to e-petitioning could be divided into short-term and long-term ones: addressing immediate environmental problems is an initial expectation, but any environmental participation endeavor increases the quality of governance and public awareness and eventually results in more effective environmental problem solving. It is not useless to attach long-term goals and expectations to e-petitioning campaigns, since they set the ground for the way environmental issues are solved in the future. Such expectations could be included in the short text of the petitions, to convince the public of the added value of participation on the long term.

From the public authorities' perspective - can e-petitions provide the basis for more inclusive participatory instruments?

When asked what their impression was regarding public hearings and consultations initiated by public authorities and their explanation for low public participation with these procedures, the answers all supported the legalistic perspective. The experts interviewed mentioned EU requirements / mechanisms imposed by EU Directives, a legal formality that has to be checked before the permit / act / authorization is issued, in order to make sure that decisions are not contested in court for procedural reasons and to limit complaints by community members.

Respondents mentioned barriers to public participation during the policy process, including implementation: in general, no tradition of public participation (other than electoral processes), low administrative capacity at the local level, lack of expertise in participation in environmental matters on both sides, the authorities and civil society organizations, institutional framework deficiencies at the central level (fragmented competencies between different institutions - e.g. Romania has a Ministry for the Environment and a separate Ministry for Water and Forests, and several central agencies dealing with separate environmental fields - National Agency for Environmental Protection, National Agency for Protected Areas, Administration of the Biosphere Reserve the Danube Delta, Administration for the Environmental Fund, etc.).

Another constant source of deception (by the authorities) is the decision-making locus (EU level) and lack of capacity to influence decision-making at this level. There is a general official discourse of over-regulation from the EU level in the environmental field and imposed decisions, and this widespread discourse affects public attitudes towards participation, since the public fails to see the state discretion offered by directives or the implementation mechanisms, or the fact that the little participation that does occur is mandated by EU legislation and done for fear of infringement procedures.

In this context, platforms supporting e-petitions and other forms of environmental participation offer more comprehensive information and participation opportunities than what the public sector currently offers as participation options. These platforms become a good practice for the public authorities (especially municipalities) to follow.

From the civil society perspective - do you see e-petitioning as a form of participation or rather as a defense mechanism in situations of both state and market failure? 
Experts see e-petitions mostly as a last resort defense mechanism, especially when citizens are faced with government failure (permitting without including consultation results, corruption, environmental discrimination, etc.).

How prominent is the role of virtual communities in environmental decision-making in Romania? Can virtual communities raise general awareness on environmental matters affecting communities?

Experts are aware of the presence of an emergent virtual community in the environmental field in the last few years. They continually build their capacity on keeping on the public agenda the most pressing environmental problems in Romania (waste, deforestation, mining projects), but with an increasing public credibility due to their independence. They have large reach on social networks and can mobilize rapidly to gather support for their e-petitons and other e-campaigns. The only worry is that recent civil involvement projects regarded fight against corruption and this would place them too close to politics (by initiating e-petitions for removing from office the Romanian Ombudsman). It is a matter of debate, however, if they reach to people who are most likely to be victims of environmental discrimination exclusively by online means of communication. The most exposed and vulnerable communities are not the likely public of environmental campaigns using online tools.

\section{Conclusions}

This section is not a list of solution proposals. These are unlimited, as is the potential and opportunities offered by the transition to environmental governance, increasing levels of education, awareness and interest in environmental matters and the e-tools available to foster good governance in the environmental field. There are, however, a few pre-requisites for such endless solutions to be at hand for public, private or civic organizations working for good environmental governance.

One such pre-requisite is the administrative self-reform with regard to transparency and public participation. As stated before, the tradition of formal / legalistic participation has to be replaced by internalized participatory processes linked to concrete outputs, such as quality of environmental solutions, effective governance, transparency and accountability in environmental matters, sustainability, etc. After this self-reforming process, the public administration can make other transitions with regard to participation mechanisms: from information to consultation, from consultation to involvement, from involvement to partnership with the citizen in environmental decision-making. Awareness, education, community building and values consolidation are achieved at all levels of public participation.

Until recently there wasn't any relevant public participation in environmental matters in Romania, citizens readily accepted state decisions and / or expert authority. The recent rise of e-petitions reflects a major change in this paradigm.

\section{References}

[1] BUZOGÁNY, A.: Romania: Environmental Governance - Form without Substance, in: T.A. Börzel (ed.), Coping with Accession to the European Union, New Model of Environmental Governance, Palgrave Macmillan, 2009, pp. 169-191.

[2] CAPITAL (Business magazine), 'The bomb related to unrecycled packaging waste will explode in supermarket prices', January $25^{\text {th }}, 2016$, [Online] at http://www.capital.ro/ 
negocierile-au-esuat-gunoaiele-nereciclate-aruncate-in-bratele-lui-ciolos.html, accessed on March $10^{\text {th }}, 2016$.

[3] FOREST STEWARDSHIP COUNCIL (FSC), Decision to disassociate in case Holzindustrie Schweighofer (HS), [Online] at https://ic.fsc.org/en/what-is-fsc/what-we-do/disputeresolution/current-cases/holzindustrie-schweighofer-hs, accessed on March 10 ${ }^{\text {th }}, 2016$.

[4] GANDUL (Newspaper), 'Billion dollar scandal on the waste market. 2,000 companies complain that are being taken out of the game by the new law on waste management services: who is the politician directly interested in the law being implemented', February $14^{\text {th }}, 2014$, [Online] at http://www.gandul.info/stiri/scandal-de-un-miliard-de-euro-pe-piata-deseurilor-2000-de-firme-se-plang-ca-sunt-scoase-din-joc-prin-noua-lege-a-salubrizarii-cine-e-deputatuldirect-interesat-ca-legea-sa-treaca-12121748, accessed on March 10 2016.

[5] Government Ordinance no. 27/30.01.2002 on regulating the activity of solving petitions, published in the Official Journal of Romania no. 84 from 1.02.2002.

[6] JACOBY, J.B.: Moving From Stakeholder to Citizen Leadership, in: D. Rigling Gallagher (ed.), Environmental Leadership. A Reference Handbook, vol. 1, Perspectives on Environmental Leadership, Sage, Thousand Oaks, 2012, pp.336-344.

[7] ROYO, S., YETANO, A. and ACERETE, B.: E-Participation and Environmental Protection: Are Local Governments Really Committed?, in: Public Administration Review, vol. 74, no. 1, 2013, pp.87-98.

[8] THALER, A.D., ZELNIO, K.A., FREITAG, A., MACPHERSON, R., SHIFFMAN, D., BIK, H., GOLDSTEIN, M.C. and MCCLAIN, C.: Digital Environmentalism, in: D. Rigling Gallagher (ed.), Environmental Leadership. A Reference Handbook, vol. 1, Perspectives on Environmental Leadership, Sage, Thousand Oaks, 2012, pp.364-373.

[9] WESSELINK, A., PAAVOLA, J., FRITSCH, O. and RENN, O.: Rationales for Public Participation in Environmental Policy and Governance: Practitioners' Perspectives, in: Environment and Planning A, vol. 43, 2011, pp.2688-2704. 